\title{
Sporulation in Bacillus subtilis. Genetic Analysis of Oligosporogenous Mutants
}

\author{
By J. G. COOTE \\ Microbiology Unit, Department of Biochemistry, University of Oxford, \\ South Parks Road, Oxford, $O X$ I $3 Q U$
}

(Accepted for publication 23 December 1971)

SUMMARY

Mutations in 30 oligosporogenous (Osp) mutants of Bacillus subtilis have been mapped by transduction with phage PBS-I. The sporulation phenotype of these mutants had previously been characterized biochemically and morphologically. The mutations are situated in areas of the genome previously shown to be occupied by asporogenous $\left(\mathrm{Sp}^{-}\right)$mutations. Data from reciprocal transformation between Osp and $\mathrm{Sp}^{-}$mutations of indistinguishable phenotype suggest that one of the Osp mutations and at least one of the $\mathrm{Sp}^{-}$mutations may be located within the same gene.

\section{INTRODUCTION}

In a previous paper the correlation of biochemical events with morphological changes was shown to be the same in oligosporogenous (Osp) and asporogenous $\left(\mathrm{Sp}^{-}\right)$mutants of Bacillus subtilis (Coote, 1972). Only Osp mutants with normal growth in a number of media were selected so as to avoid, as far as was possible, mutants having defective sporulation because of damage to a vegetative function (Spizizen, 1965; Bott \& Davidoff-Abelson, I966; Fortnagel \& Freese, I968). Over half of these Osp mutants exhibited a phenotype previously identified with the $\mathrm{Sp}^{-}$character. This suggested that instead of Osp mutants being considered as a distinct class of sporulation mutant, for example, as regulatory mutants (Hanson, Peterson \& Yousten, 1970), the Osp and $\mathrm{Sp}^{-}$states might, in some instances at least, be alternative expressions of mutation within a single gene. This would have to be shown by mapping, and the only evidence on this point which seems so far to have been presented was by Rouyard, Ionesco \& Schaeffer (1967) whose data from reciprocal transformation between an Osp mutant and a $\mathrm{Sp}^{-}$mutant blocked at stage II of sporulation indicated that the two mutations may have been located within the same gene.

In this paper I report the mapping by phage PBS-I mediated transduction of the thirty Osp mutants previously described (Coote, 1972). Also included is an analysis by transformation of six mutants (two Osp and four $\mathrm{Sp}^{-}$) exhibiting a similar sporulation phenotype and all linked by transduction to the phe-I2 marker. The Osp mutations are located in the same areas of the genome as $\mathrm{Sp}^{-}$mutations. In addition evidence is given to indicate that an Osp mutation and a $\mathrm{Sp}^{-}$mutation may be located within the same gene.

\section{METHODS}

Organisms. Bacillus subtilis MARBURG I68 $\operatorname{trpC}$ ) was used which, although it is an auxotroph, sporulates normally and is referred to as the wild-type. The Osp mutants were derived from this strain as described previously (Coote, 1972). A prototrophic MARBURG 
Table I. Strains of Bacillus subtilis used for the transduction analysis

\begin{tabular}{|c|c|c|}
\hline Mutant & Genotype & Origin \\
\hline GSY254 & $l y s-I, \operatorname{trp} C 2$ & C. Anagnostopoulos \\
\hline GYS289 & $u r a-I, \operatorname{trp} C 2$ & C. Anagnostopoulos \\
\hline GSY334 & leu-8 & C. Anagnostopoulos \\
\hline GSY342 & metB5 & C. Anagnostopoulos \\
\hline GSYIO2O & purB6, hisB2 & C. Anagnostopoulos \\
\hline GSYIO2I & purAI6, hisBz & C. Anagnostopoulos \\
\hline BDI 12 & $\operatorname{cys} A r_{4}$ & D. Dubnau \\
\hline BDI63 & hisAI, $\arg C_{4}$ & D. Dubnau \\
\hline BD40 & phe-12, $\arg A_{3}$ & D. Dubnau \\
\hline BD70 & $\operatorname{met} A 3, \operatorname{trp} C 2$ & D. Dubnau \\
\hline BDI I I & $t h r-5, \operatorname{trp} C 2, c y s B_{3}$ & D. Dubnau \\
\hline MB2 & lys-r, hisB2 & P. Piggot \\
\hline MB3 & phe-12 & P. Piggot \\
\hline MB8 & $h i s A I$ & P. Piggot \\
\hline
\end{tabular}

strain of B. subtilis was obtained from Dr S. R. Ayad. The auxotrophic strains used for the genetic analysis are listed in Table $\mathrm{I}$.

Terminology. Stages $\mathrm{O}$ to VI are the generally accepted stages of spore formation and have been described previously (Coote, 1972). Stages $O$ and I were not distinguished in electron micrographs and mutants of these types have been grouped together as stage $O$ mutants.

Media. PAB was antibiotic assay medium no. 3 (Difco, Detroit, U.S.A.) BHIB medium was $2.5 \%$ Brain Heart Infusion Broth (Oxoid, London) plus $0.5 \%$ yeast extract (Difco). Glutamate minimal medium and lactate-glutamate minimal agar plates were prepared as described previously (Coote, I972). PTM and TM media were media I and II as described by Ayad \& Barker (1969).

Preparation of transducing lysates. The method used was essentially that of Karamata \& Gross (1970). Donor cells were grown overnight at $30^{\circ} \mathrm{C}$ in PAB, checked to ensure that they were motile and then diluted into 4 flasks containing BHIB medium to give $5 \times 10^{6} \mathrm{cells} / \mathrm{ml}$. The cells were infected with $0.1 \mathrm{ml}$ PBS-I stock lysate at different times $(0,30,60$ and $90 \mathrm{~min})$ following the dilution in BHIB. The cultures were incubated with shaking for 8 to $\mathrm{io} h$ at $37^{\circ} \mathrm{C}$ and then allowed to lyse overnight at room temperature without aeration. The bacterial debris was removed by centrifugation and the supernatants stored at $4{ }^{\circ} \mathrm{C}$ in sterile vials containing a few drops of chloroform. The vials were well shaken and left for I day before use to ensure that all bacteria had been killed. Originally, lysates were treated with DNase before shaking with chloroform, but this was later omitted because no transforming activity has been detected under the conditions used for transduction. Transducing activities of the lysates prepared at the different times varied. Transducing activity is unrelated to the active phage titre (Karamata \& Gross, 1970).

Transduction. Recipient cells were grown in BHIB medium at $37^{\circ} \mathrm{C}$ until late log phase $(0.5 \mathrm{mg}$ dry wt $/ \mathrm{ml})$. If the cells were motile $\mathrm{I} \mathrm{ml}$ of the suspension was added to $0 . \mathrm{I} \mathrm{ml}$ of a lysate and incubated at $37^{\circ} \mathrm{C}$ with shaking for $30 \mathrm{~min}$. The cells were then centrifuged, resuspended in an equal volume of glutamate minimal medium and $0^{-1} \mathrm{ml}$ of this suspension spread on a lactate-glutamate minimal agar plate. The sterility of the lysate was tested on nutrient agar (Oxoid) and reversion of the recipient bacteria was tested by plating $0.1 \mathrm{ml}$ of a suspension not mixed with phage, but otherwise treated in an identical manner. When the recipient was a double auxotroph the requirement not being selected for was added to the plates before the addition of the cell suspension.

Transformation. DNA was extracted by the 4-aminosalicylate-phenol method of Kelly \& 
Pritchard (1965). The DNA fibres were collected by winding on to a glass rod, dipped in $95 \%(\mathrm{v} / \mathrm{v})$ ethanol, and redissolved in $5 \mathrm{ml}$ of a solution of $\mathrm{NaCl}$ (IO mM) plus EDTA (I mM). The solution was stored at $4{ }^{\circ} \mathrm{C}$ overnight and the following day the concentration of saline was increased to $0^{\circ} \mathrm{I} M$. The DNA was stored frozen in small volumes until used. It was not treated with RNase. The transformation procedure was performed according to Ayad \& Barker (1969). Recipients were grown overnight at $37^{\circ} \mathrm{C}$ in PTM medium. They were then diluted with the same medium to approximately $0.05 \mathrm{mg}$ dry $\mathrm{wt} / \mathrm{ml}$ and shaken vigorously at $37^{\circ} \mathrm{C}$ until late $\log$ phase $(0.5 \mathrm{mg}$ dry $\mathrm{wt} / \mathrm{ml})$. Five $\mathrm{ml}$ of the culture was added to $18 \mathrm{ml}$ of warmed TM medium which lacked the amino acid being selected for. The cells were shaken gently for 40 to $50 \mathrm{~min}$, two I $\mathrm{ml}$ samples then removed and one of them added to DNA. The cells were shaken for a further $\mathrm{I} h$ at $37^{\circ} \mathrm{C}$ and $\mathrm{o} \cdot \mathrm{I} \mathrm{ml}$ of each suspension plated directly on to lactate-glutamate minimal agar. Sterility of the DNA was checked by spreading a drop on to nutrient agar. All transformations were performed using saturating concentrations of DNA $(2 \mu \mathrm{g} / \mathrm{ml})$.

Selection and screening of recombinants. Generally, for transduction, lysates resulting from the infection of the Osp strain with phage were used to transduce an auxotrophic sporulating strain to prototrophy. Recipient strains were chosen having auxotrophic requirements which between them covered the genetic map (see Dubnau, 1970). Both prototrophic transductants and transformants were isolated on lactate-glutamate minimal agar and left for several days to allow development of the pigment associated with sporulation in this strain (Iichinska, 1960; Schaeffer \& Ionesco, 1960). Colonies were then scored as $\mathrm{Sp}^{+}$(brown) or Osp (white or light brown). Oligosporogenous transductants and transformants were examined in the phase-contrast microscope to ensure, at least in the case of mutants forming feebly refractile spores, that they they had the phenotype of the original mutant and in any case to ensure that they were still Osp in character.

Criteria of linkage. The chromosomal location of the Osp mutations was determined by measuring the co-transduction of the Osp characters with auxotrophic markers. Percentage recombination was the percentage of prototrophic transductants which inherited the unselected Osp marker subtracted from Ioo and this figure was used as a rough measure of the distance between two markers. Three-factor crosses in the lys region were done using lysates from Osp, $l y s^{+}, \operatorname{tr} p C$ as donor with $\mathrm{Sp}^{+}, l y s-I$, $t r p^{+}$as recipient (MB2). Lys $s^{+}$transductants were selected and scored as Osp or $\mathrm{Sp}^{+}$. They were then tested on lactate-glutamate minimal agar lacking tryptophan to determine the number of $\operatorname{trp} C$ recombinants. The position of the unknown marker, Osp, with respect to markers of known location, lys and trp, was determined by analysing the distribution of recombinants from the cross.

For transformation, the linkage relationship between two mutations was determined by two-point crosses and calculated by the method of Lacks \& Hotchkiss (1960). Oligosporogenous or asporogenous mutants under investigation, together with the parent wild-type strain, were initially transformed to prototrophy using DNA prepared from the $\operatorname{trp}^{+}$strain of Bacillus subtilis. DNA was then prepared from each prototrophic mutant and the prototrophic derivative of the parent strain. Any one mutant DNA preparation along with the wild-type DNA preparation were each used in separate experiments to transform a $\operatorname{trp} C$ mutant strain to prototrophy. Trp $p^{+}$transformants from both crosses were selected on lactate-glutamate minimal agar lacking tryptophan and after incubation at $37^{\circ} \mathrm{C}$ for 2 to 3 days any $\mathrm{Sp}^{+}$recombinants were clearly distinguishable among the $t r p^{+}$transformants. At the saturating concentration of DNA which was used, wild-type DNA and mutant recipient normally gave between 5 and $10 \% \mathrm{Sp}^{+}$colonies among the selected trp $^{+}$transformants, i.e. one in to to 20 cells transformed to $\operatorname{trp}^{+}$were able to take up a second piece 
of DNA possessing the unlinked sporulation marker. A diagrammatic representation of the two crosses is shown below:

(1)
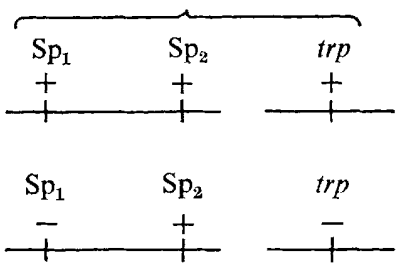

(2)

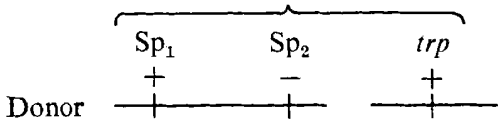

Donor

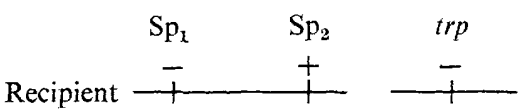

The ratio of $\mathrm{Sp}^{+}$to $\mathrm{trp}^{+}$transformants was scored for both crosses and the relative distance between the two mutational sites given by the equation: Recombination Index (R.I.) $=\mathrm{Sp}^{+} /$trp ${ }^{+}$(mutant DNA)/Sp ${ }^{+} / t r p^{+}$(wild-type DNA). The R.I. is one if the mutations are unlinked and falls in value the more closely linked they are. Each DNA preparation was used to transform all the $\operatorname{trp} C$ mutants in turn to prototrophy and in this way transformation was performed reciprocally for each mutant. For each recipient the ratio of $\mathrm{Sp}^{+}$to $\mathrm{trp}^{+}$ transformants was scored for both mutant and wild-type donor.

\section{RESULTS}

Genetic location by transduction of the Osp mutations. Transducing lysates prepared from each of the mutants were used to test for co-transduction of the Osp character with each of the auxotrophic markers (Table I). The distribution of the markers on the genome (Fig. I) is that of Dubnau (1970). Osp mutations were situated mainly in two areas of the genome. Eight of the mutations were located in the his A, ura-I region (Fig. 2). Of these YIO, W5, WIo and $\mathbf{P} 2$ were linked to both met $A$ and $u r a-I$ markers. Now these auxotrophic markers are co-transduced at low frequency (Fig. I) and so it would seem that the mutations lie between these markers. PI 3 was placed to the right of $u r a-I$ as it showed only slight linkage to met $A$, but it is clear that the distances in this region are not additive (see also Ionesco, Michel, Cami \& Schaeffer, 1970). For this reason the mutations W5, P2 and PI3 surrounding the ura- $I$ marker have been placed in brackets.

Seventeen of the mutations were located in the phe-I 2, lys-I segment (Fig. 3). Mutations that were linked to both phe-I2 and leu- 8 were placed to the right of phe-I2 because in all instances the percentage recombination of the sporulation marker with leu- 8 was greater than the percentage recombination of the phe-I2 marker with leu- 8 (see Fig. I). However, because of fluctuation in recombination values from one experiment to another the linear order of the mutations closely linked to phe-12 is uncertain and so they are again placed in brackets. All twelve mutations linked to lys- $I$ were placed to the left or right of this marker by means of three-factor crosses, examples of which are given in Table 2. Linkage to trpC was determined in all cases by noting the number of $\mathrm{Sp}^{+}, t_{r}{ }^{+}$recombinants after using phage prepared on Bacillus subtilis $\left(\operatorname{trp}^{+}\right)$to transduce Osp strains $(\operatorname{trp} C)$ to prototrophy. The mutations to the left of $l y s-I$ were placed in linear order except for two groups which were placed in brackets (Fig. 3). The percentage recombinations of these groups with the lys-I and $\operatorname{tr} P C$ markers are given as averages and they were actually PIo ( 46 and 64 respectively), PI 2 ( 45 and 65), WI 2 (47 and 68), X3 (52 and 76), Y9 (50 and 68) and P4 (49 and 7 I).

'Two mutations, ZIOA and PI4, were linked to the cys $A$ marker with percentage recombination values of 30 and 27 respectively. The three remaining mutations (Z12, Z29 and DG47) 
pur Al6 $\operatorname{cis} A 14$

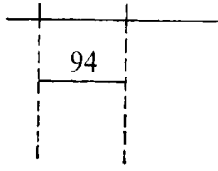

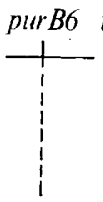
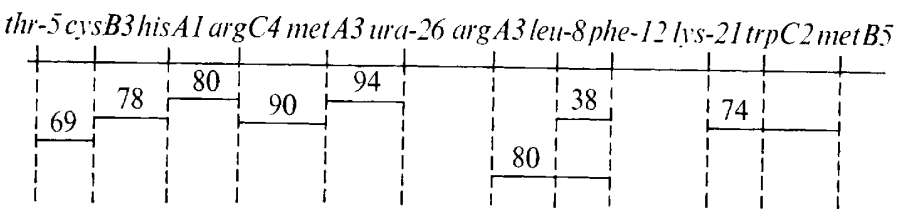

Fig. I. The distribution of markers on the Bacillus subtilis genome according to Dubnau (1970). The numbers are percentage recombination obtained from two-factor transduction crosses and are taken from a previous paper (Dubnau et al. 1967 ).

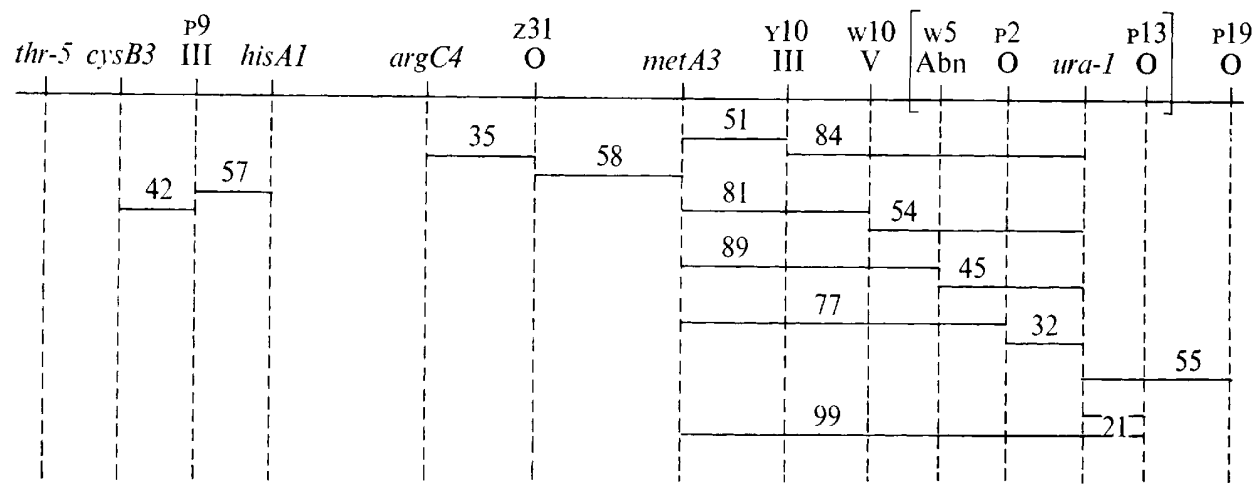

Fig. 2. Map of the positions of Osp mutations obtained by two-factor transduction crosses. The numbers are percentage recombination and are the average of at least two separate experiments in which 100 to 1000 colonies were scored for each cross. The absence of a number between an auxotrophic marker and a sporulation marker indicates that no linkage was detected. The Roman numerals are the stages of sporulation at which the mutants were blocked and Abn means abnormal development (see Coote, 1972).

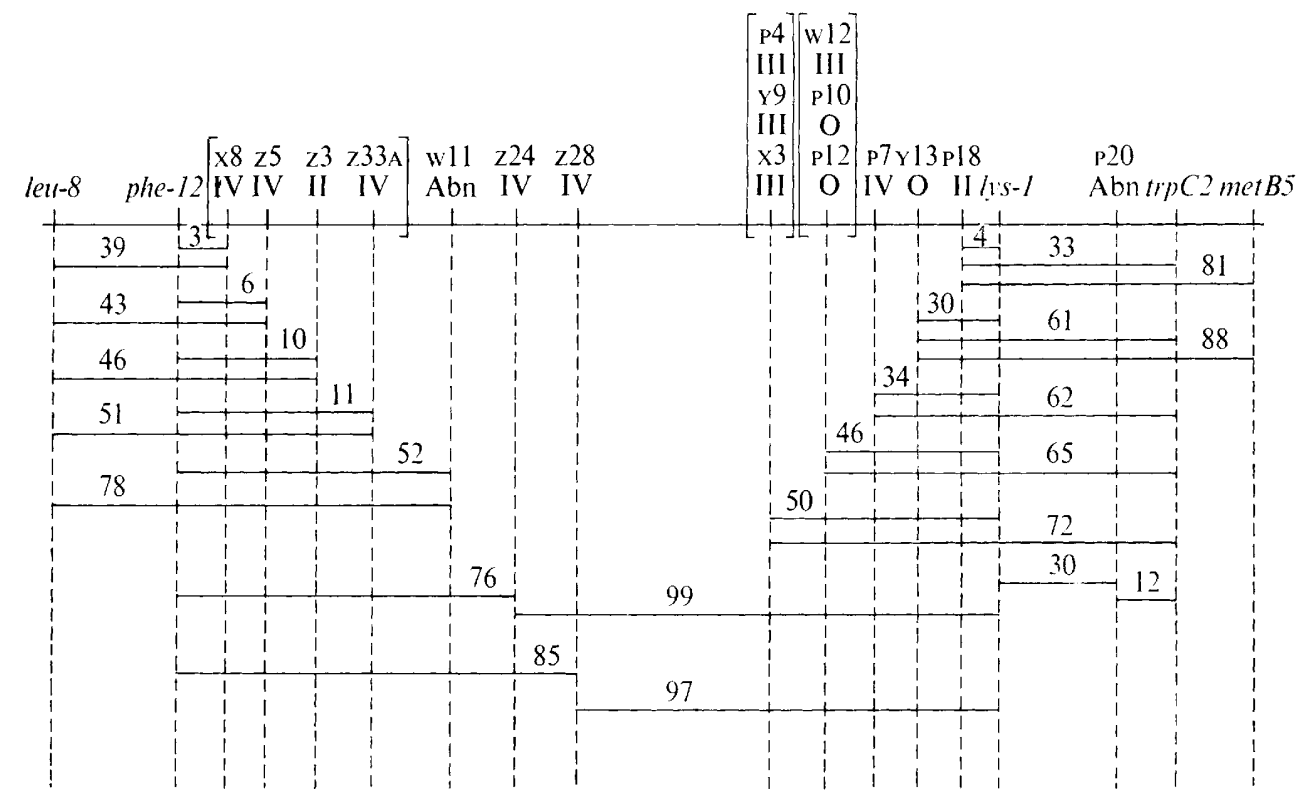

Fig. 3. Map of the positions of Osp mutations obtained by two and three-factor transduction crosses. For further details see Fig. 2 and Table 2. 
Table 2. Orientation of Osp mutations with respect to the lys-I and trpC markers by means of three-factor crosses

\begin{tabular}{|c|c|c|c|c|}
\hline \multirow[b]{2}{*}{$\begin{array}{c}\text { Donor } \\
\text { genotype }\end{array}$} & \multirow[b]{2}{*}{$\begin{array}{l}\text { Recipient } \\
\text { genotype }\end{array}$} & \multicolumn{2}{|c|}{ Recombinants } & \multirow{2}{*}{$\begin{array}{l}\text { Implied } \\
\text { order }\end{array}$} \\
\hline & & Type & No. & \\
\hline $\mathrm{Y} 13, \operatorname{trp} C 2$ & lys-I, (hisBz) & $\begin{array}{l}\text { lys }{ }^{+} \mathrm{Y} 13 \text { trp } \\
\text { lys } \\
\text { lys }^{+} \text {Y }^{+} S \text { trp }^{+} \\
\text {lysp } \\
l y s^{+} S p^{+} t r p^{-}\end{array}$ & $\begin{array}{l}63 \\
15 \\
24 \\
48\end{array}$ & $\mathrm{Y} 13, l y s, t r p$ \\
\hline $\mathbf{P} 20, \operatorname{trp} C 2$ & lys-I, (hisB2) & $\begin{array}{l}\text { lys }{ }^{+} \mathbf{P} 20 t r p^{+} \\
\text {lys } \\
\text { lys } 20 t r p^{-} \\
\text {lys }^{+} S p^{+} \text {trp }^{+} \\
l y s^{+} S p^{+} t r p^{-}\end{array}$ & $\begin{array}{r}12 \\
52 \\
61 \\
0\end{array}$ & $l y s, \mathbf{P} 20, \operatorname{trp}$ \\
\hline
\end{tabular}

Table 3. Percentage recombination determined by two-factor transduction crosses of five Osp and four $\mathrm{Sp}^{-}$mutants all reaching stage IV of spore development

Heat resistance values were obtained at $7 \mathrm{~h}$ after transfer of cells into a medium to initiate sporulation and are taken from a previous paper (Coote, 1972). They were expressed as a percentage of the wild-type values which were taken as 100 .

\begin{tabular}{|c|c|c|c|c|c|}
\hline \multirow[b]{2}{*}{ Mutant } & \multirow[b]{2}{*}{ Type } & \multirow{2}{*}{$\begin{array}{l}\text { Heat } \\
\text { resistance }\end{array}$} & \multicolumn{3}{|c|}{ with auxotrophic markers } \\
\hline & & & leu-8 & phe-I2 & $l y s-I$ \\
\hline x8 & Osp & $I \cdot O$ & 39 & 3 & 100 \\
\hline Z33A & Osp & $I \cdot O$ & $5 I$ & I I & 100 \\
\hline $\mathrm{z} 5$ & Osp & $0 \cdot 2$ & 43 & 6 & 100 \\
\hline $\mathrm{z} 24$ & Osp & 0.5 & 100 & 76 & 99 \\
\hline z28 & Osp & O.I & 100 & 85 & 97 \\
\hline E3I & $\mathrm{Sp}^{-}$ & $<0.0001$ & 100 & 75 & 96 \\
\hline $\mathbf{z 7}$ & $\mathrm{Sp}^{-}$ & $<0.0001$ & 100 & 76 & 98 \\
\hline $\mathrm{x} 2$ & $\mathrm{Sp}^{-}$ & $<0.000 \mathrm{I}$ & 100 & 88 & 96 \\
\hline w3 & $\mathrm{Sp}^{-}$ & $<0.0001$ & 100 & $9 \mathrm{I}$ & 97 \\
\hline
\end{tabular}

showed no linkage with the available markers. These genes presumably lie in areas of the map not covered by the markers used here or are due to multiple unlinked lesions.

Transformation analysis of stage IV mutants linked to the phe locus. Linked to the phe-I2 marker are five Osp mutations (Fig. 3) which cause the bulk of the cells to be blocked at stage IV in the sporulation process. They are Osp to varying degrees (Table 3), but the majority of cells in each case produced feebly refractile prespores under sporulation conditions (Coote, 1972). Eventually the mother cells lysed and released the unfinished spores into the medium. The feeble refractility and the degeneration of the mother cell were plainly visible in the phase-contrast microscope and facilitated a clear recognition of this phenotype. Four $\mathrm{Sp}^{-}$mutants with an identical phenotype were also shown to be linked to the phe-I2 marker (Table 3). One of these (E3I) was isolated by S. C. Warren and has been previously described (Piggot \& Mandelstam, 1972).

The purpose of the analysis by transformation was to try to determine whether an Osp mutation and a $\mathrm{Sp}^{-}$mutation were located within the same gene. Unfortunately, no $\mathrm{Sp}^{-}$ stage IV mutations were closely linked to the phe-I2 marker (Table 3 ) so the group loosely linked to this marker and which included both $\mathrm{Sp}^{-}$and Osp mutations had to be studied. It was assumed that the mutations loosely linked by transduction to the phe-12 marker would not be linked to this marker by transformation in which a much smaller piece of DNA 
Table 4. Reciprocal crosses by transformation of stage IV mutants linked by transduction to the phe-I2 marker

Values are R.I. $\times I 00$. NR means not recorded as the numbers of $t r p^{+}$transformants from these crosses were too small to be meaningful. In all other instances between 250 and 1500 trp $^{+}$transformants were scored for $\mathrm{Sp}^{+}$or mutant phenotype.

\begin{tabular}{|c|c|c|c|c|c|}
\hline \multirow[b]{2}{*}{$\begin{array}{l}\text { Recipient } \\
\left(t r p^{-}\right)\end{array}$} & \multicolumn{5}{|c|}{ Donor DNA $\left(t r p^{+}\right)$} \\
\hline & $\begin{array}{c}\mathrm{Z7} \\
\mathrm{Sp}^{-}\end{array}$ & $\begin{array}{c}\mathrm{X} 2 \\
\mathrm{Sp}^{-}\end{array}$ & $\begin{array}{l}\text { Z28 } \\
\text { Osp }\end{array}$ & $\begin{array}{l}\text { E3 I } \\
\text { Sp }^{-}\end{array}$ & $\begin{array}{l}\text { w3 } \\
\mathrm{Sp}^{-}\end{array}$ \\
\hline 27 & 0.0 & $14 \cdot 8$ & I. 8 & $23 \cdot 6$ & $2 \cdot 5$ \\
\hline $\mathrm{X} 2$ & II 3 & $0 \cdot 0$ & $8 \cdot 7$ & $5 \cdot 3$ & $15 \cdot 4$ \\
\hline $\mathrm{Z} 28$ & $3 \cdot 2$ & $7 \cdot 3$ & 0.0 & $3 \cdot 0$ & $3 \cdot 6$ \\
\hline E3 I & $20 \cdot 8$ & 10.5 & $6 \cdot 2$ & 0.0 & $13 \cdot 0$ \\
\hline w3 & NR & $9 \cdot 0$ & NR & NR & 0.0 \\
\hline w5 & $87 \cdot 0$ & $92 \cdot 0$ & 110.0 & $88 \cdot 0$ & $\mathrm{I} 2 \mathrm{I} \cdot \mathrm{O}$ \\
\hline
\end{tabular}

Table 5. Examples of the ratios of $\mathrm{Sp}^{+}$to $\mathrm{rp}^{+}$transformants obtained by reciprocal transformation

The figures show the number of $\mathrm{Sp}^{+}$recombinants (numerator) and the total number of $\operatorname{trp}^{+}$ transformants (denominator). The ratios used in calculating the recombination index (see Methods) are shown in parentheses.

\begin{tabular}{|c|c|c|c|c|c|}
\hline \multirow[b]{2}{*}{ Recipient } & \multirow[b]{2}{*}{$\left(t r p^{-}\right) \ldots$} & \\
\hline & & $\begin{array}{c}\mathrm{Z7} \\
\mathrm{Sp}^{-}\end{array}$ & $\begin{array}{l}\text { Z28 } \\
\text { Osp }\end{array}$ & $\begin{array}{l}\mathrm{E} 3 \mathrm{I} \\
\mathrm{Sp}^{-}\end{array}$ & Wild-type \\
\hline $\mathrm{z} 7$ & $\begin{array}{l}\text { Expt I } \\
\text { Expt } 2\end{array}$ & $\begin{array}{l}o / 1270 \\
0 / 944\end{array}$ & $\begin{array}{l}\text { I/94I (0.00I I) } \\
0 / 646\end{array}$ & $\begin{array}{l}14 / 1094(0.013) \\
7 / 395(0.018)\end{array}$ & $\begin{array}{l}51 / 850(0.06) \\
66 / 926(0.07)\end{array}$ \\
\hline Z28 & $\begin{array}{l}\text { Expt I } \\
\text { Expt } 2\end{array}$ & $\begin{array}{l}2 / 840(0.0024) \\
3 / 818(0.0036)\end{array}$ & $\begin{array}{l}0 / 235 \\
0 / 472\end{array}$ & $\begin{array}{l}2 / 503(0.004) \\
2 / 1108(0.0018)\end{array}$ & $\begin{array}{l}23 / 219(0.11) \\
33 / 412(0.08)\end{array}$ \\
\hline E3I & $\begin{array}{l}\text { Expt I } \\
\text { Expt } 2\end{array}$ & $\begin{array}{l}9 / 513(0.018) \\
3 / 310(0.0097)\end{array}$ & $\begin{array}{l}2 / 712(0.0028) \\
2 / 515(0.0039)\end{array}$ & $\begin{array}{l}0 / 255 \\
0 / 889\end{array}$ & $\begin{array}{l}95 / 935(0.1) \\
16 / 395(0.04)\end{array}$ \\
\hline
\end{tabular}

is transferred than in PBS-I transduction (Dubnau, Goldthwaite, Smith \& Marmur, 1967). The unavailability of a linked marker for these mutations prompted the use of the recombination index method (see Methods). This procedure avoids variations in competence of recipients and variations in efficiency of DNA preparations by relating the transfer of a given marker to the transfer of an outside unlinked marker, in this case tryptophan dependence.

Reciprocal transformation was performed by the procedure described in Methods. The results (Table 4) suggest that all five mutations loosely linked to phe-12 are closely linked to each other. The ratio of $\mathrm{Sp}^{+} /$trp $^{+}$recombinants used in calculating the recombination index was in all cases the average from at least two separate transformations. Examples of actual numbers obtained for three linked mutations are given in Table 5. Mutant Z24 yielded only an average of $0.2 \%$ (instead of the expected 5 to $10 \%$ ) Sp+ colonies among the total $t r p^{+}$transformants when used as recipient with wild-type DNA as donor and no increase in the number of $\mathrm{Sp}^{+}$colonies was obtained if the DNA concentration was increased to $5 \mu \mathrm{g} / \mathrm{ml}$. Z24 was presumed therefore to be a double mutant, was not further investigated and is not included in Table 4. Mutant w5 was included as a control and it showed no linkage to any other mutation which was in agreement with its location in the metA, ura-I region of the chromosome. No $\mathrm{Sp}^{+}$colonies were detected when DNA prepared from the trp ${ }^{+}$ 
derivative of a mutant was used to transform the same $\operatorname{trp} C$ strain to prototrophy. This indicated that back-mutation of the recipients was not an important factor, so that although the numbers of $\mathrm{Sp}^{+}$colonies counted in some crosses were extremely low (Table 5), they were nevertheless considered to be significant.

\section{DISCUSSION}

Only one of the Osp mutations mapped P9, lying between $\operatorname{cys} B$ and his $A$, has been located in one of the regions of the genome where tricarboxylic acid cycle mutations have been shown to map (Rutberg \& Hoch, 1970). This indicates that the selection procedure used during isolation of the mutants (Coote, 1972) was probably successful in excluding mutants which were oligosporogenous because of a damaged tricarboxylic acid cycle.

The majority of the Osp mutations were located between the phe-I2 and lys-I markers near the terminal end of the chromosome where a majority of $\mathrm{Sp}^{-}$mutations have been previously shown to map (Hoch \& Spizizen, I969; Rogolsky, 1969; Takahashi, 1969; Ionesco et al. 1970; Piggot \& Mandelstam, 1972). All but two of the remainder of the Osp mutations showing linkage were situated in the region which stretched from $c y s B$ to the right of ura-r in an area also occupied by Sp- genes (Rogolsky, 1969; Ionesco et al. 1970; Piggot \& Mandelstam, 1972).

It is worth noting that the positions of some of the Osp mutations within the phe-12, lys-I segment are very similar to those of previously located $\mathrm{Sp}^{-}$mutations. Stage II $\mathrm{Sp}^{-}$ mutations have been placed a similar distance from lys-I as PI8 (Ionesco et al. 1970; P. Piggot, personal communication). The stage $O$ and I Osp mutations lie between 30 and 50 units to the left of $l y s-r$ and similar $\mathrm{Sp}^{-}$mutations have been located between 35 and 50 units to the left of this marker (Hoch \& Spizizen, 1969; Hoch, 1971). In addition stage III and IV Sp- mutations have been reported in similar positions in this region to the stage III and IV Osp mutations (Hoch \& Spizizen, 1969; Ionesco et al. 1970; Piggot \& Mandelstam, 1972). In so far as it is possible to compare transduction data from different laboratories these similar groupings of the Osp and $\mathrm{Sp}^{-}$mutations are consistent with the idea that mutation in one gene can produce either an Osp or a $\mathrm{Sp}^{-}$phenotype. The stage IV Osp mutations loosely linked to phe-I2 also showed a weak linkage to lys-I which is in agreement with the genetic continuity recently found in this region (Ionesco \& Cami, I969; Ionesco et al. 1970). Only one Osp mutation was located to the right of the lys- $I$ marker and this produced phenotypic effects not previously described in sporulation of Bacillus subtilis (Coote, 1972). It was characterized by an accumulation of spore coat material in the mother cell cytoplasm instead of around the developing spore. It is possible that a gene concerned with the control of coat deposition is situated to the right of lys-I. A Sp- mutation producing a very similar phenotype has also been located between the $l y s-I$ and $\operatorname{trp} C$ markers (P. Piggot, personal communication).

The results of the mapping bring out other points that Osp and $\mathrm{Sp}^{-}$mutants have in common. Thus, Osp mutations associated with the same type of morphological block can be widely separated on the chromosome in the same way as $\mathrm{Sp}^{-}$mutations (see Ionesco et al. 1970; Piggot \& Mandelstam, 1972). For example, mutants PI4 and PI8, both of which have a similar sporulation phenotype and which lay down septa at both ends of the cell, map at opposite ends of the genome. This presumably means that interference with at least two distinct biochemical steps can produce this particular aberration. Conversely genes situated very close to each other can apparently be associated with totally different structural events. In the chromosomal segment between the phe- $r 2$ and lys-I markers stage O, II, III and IV phenotypes are present in close juxtaposition (Fig. 3). 
The possibility that mutations of similar morphology were located within a single gene cannot be judged from recombination data using transduction which are too variable to establish this (see also Hoch, 197I). For instance, in separate transduction experiments the percentage co-transfer with the phe-I2 marker of mutation $\mathrm{Z2} 8$ was $13,10,18$ and $19 \%$ and for mutation $\mathrm{z} 7$ the values with this marker were $26,20,2 \mathrm{I}$ and $28 \%$. For analysis of mutations which are closely linked transformation is more suitable because recombination between closely linked mutations is more likely to occur when the number of genes transferred in the process is so much smaller. The transformation data (Table 4) show that the mutations loosely linked to phe-I 2 by transduction (z28, E3 I, z7, X2 and w3) were all closely linked to each other. The number of cistrons comprising this linkage group could not be directly determined because without diploidy in Bacillus subtilis direct complementation is not possible. However, the maximum R.I. can be compared with that obtained from the most distant markers of mutations known to be within a single gene. In experiments with B. subtilis I 68 Carlton (1966) found a R.I. $\times$ I00 of 20 for the most distant markers within the tryptophan synthetase gene and values as high as 30 were recorded during the analysis of ornithine transcarbamylase mutants (Mahler, Neumann \& Marmur, 1963). It seems reasonable to take a value of to or less as probably representing one gene and this has been done previously by Rouyard et al. (1967). Recombination indices (Table 4) of less than 10 were obtained between the Osp mutation $\mathrm{Zz} 8$ and both $\mathrm{Sp}^{-}$mutations $\mathrm{Z7}(\mathrm{I} \cdot 8$ and $3 \cdot 2)$ and E3I $(3.0$ and $6 \cdot 2)$. The reciprocal crosses shown in Table 4 gave for the most part values which were in good agreement, but not accurate enough to ascribe an unequivocal order to the mutations. The method used suffers from the weakness for the need to count a large number of transformants, and without direct selection for $\mathrm{Sp}^{+}$recombinants only a very small number of these are detected in a cross between two closely linked mutations.

The work of Rouyard et al. (1967) showed that reciprocal transformation between a $\mathrm{Sp}^{-}$and an Osp stage II mutant yielded R.I. $\times$I0o values of between 0 and $3^{\circ} 0$. This seems to be the only other direct evidence presented to indicate that mutations in one gene may produce either the $\mathrm{Sp}^{-}$or the Osp phenotype. Low recombination values would also be obtained if the mutations were located very close to each other at the ends of adjacent genes. They would then be functionally separate, but recombination will take place across the boundary of the two genes. The recombination data (Table 4) place Osp mutation z28 between the $\mathrm{Sp}^{-}$mutations $\mathrm{Z} 7$ and $\mathrm{E}_{3} \mathrm{I}$ as $\mathrm{Z} 7$ and $\mathrm{E}_{3} \mathrm{I}$ have reciprocal values of 20.8 and 23.6 . It seems most unlikely from the recombination values that these mutations span the length of three genes unless $\mathbf{Z} 28$ is a mutation in a very small regulatory area lying between two larger genes. If this order of the mutations is correct then even if $\mathrm{z}_{7}$ and $\mathrm{z}_{2} 8$ were at the extreme ends of separate loci, it seems likely that E3 $\left(\mathrm{Sp}^{-}\right)$at least has a mutation in the same gene as $\mathrm{Z} 28$ (Osp). Another possible complicating factor is that mutants $\mathrm{Z} 7$ and $\mathrm{z2} 8$ were derived by treatment of the wild-type with $N$-methyl- $N^{\prime}$-nitro- $N$-nitrosoguanidine, a mutagen which causes induction of closely linked multiple mutations in Escherichia coli (Guerola, Ingraham \& Cerdá-Olmedo, 197I). However, reciprocal crosses (Table 4) gave similar recombination values which makes the possibility of two linked spore mutations in one or both mutants of a cross unlikely as a reason for the low numbers of $\mathrm{Sp}^{+}$recombinants.

The possibility cannot be eliminated that some Osp mutations are of a distinct regulatory nature. However, the fact that many Osp mutants have phenotypically similar $\mathrm{Sp}^{-}$counterparts (Coote, 1972), the marked similarity in the location on the genome of the two types of mutation and the evidence presented here and elsewhere (Rouyard et al. 1967) suggesting the location of an Osp mutation and its $\mathrm{Sp}^{-}$counterpart within a single gene indicate strongly 
that some Osp strains at least are probably leaky mutants. Thus, although the distinction between the two types of mutant is phenotypically very clear it may not necessarily involve separate genes for the $\mathrm{Sp}^{-}$and Osp phenotypes.

I am very grateful to Dr P. Piggot and Professor J. Mandelstam for many helpful discussions. I thank Mrs Dawn Torgerson for skilled technical assistance. The work was supported by a grant from the Science Research Council.

\section{REFERENCES}

AYAD, S. R. \& BARKER, G. R. (1969). The integration of donor and recipient deoxyribonucleic acid during transformation of Bacillus subtilis. Biochemical Journal II3, I67-I74.

Bott, K. F. \& Davidoff-Abelson, R. (1966). Altered sporulation and respiratory patterns in mutants of Bacillus subtilis induced by acridine orange. Journal of Bacteriology 92, 229-240.

Carlton, B. C. (1966). Fine-structure mapping by transformation in the tryptophan region of Bacillus subtilis. Journal of Bacteriology 91, 1795-1803.

CоOTE, J. G. (1972). Sporulation in Bacillus subtilis. Characterization of oligosporogenous mutants and comparison of their phenotypes with those of asporogenous mutants. Journal of General Microbiology 7I, I-I 5 .

DubnaU, D. (1970). Linkage map of Bacillus subtilis. In Handbook of Biochemistry, 2nd edn, Section I-39. Edited by H. A. Sober. Cleveland, Ohio: The Chemical Rubber Co.

Dubnau, D., Goldthwatte, C., Smith, I. \& Marmur, J. (1967). Genetic mapping in Bacillus subtilis. Journal of Molecular Biology 27, 163-185.

ForTNAGEL, P. \& FrEeSE, E. (1968). Analysis of sporulation mutants. II. Mutants blocked in the citric acid cycle. Journal of Bacteriology 95, I43I-I438.

Guerola, N., Ingraham, J. L. \& CerdÁ-Olmedo, E. (I97I). Induction of closely linked multiple mutations by nitrosoguanidine. Nature New Biology 230, I22-125.

Hanson, R. S., Peterson, J. A. \& Yousten, A. A. (1970). Unique biochemical events in bacterial sporulation. Annual Review of Microbiology 24, 53-90.

Носн, J. A. (197I). Genetic analysis of pleiotropic negative sporulation mutants in Bacillus subtilis. Journal of Bacteriology 105, 896-90I.

Hoch, J. A. \& SpIzızen, J. (1969). Genetic control of some early events in sporulation of Bacillus subtilis I68. In Spores, vol. Iv, pp. I I 2-I 20. Edited by L. L. Campbell. Bethesda, Maryland: American Society for Microbiology.

IICHINSKA, E. (1960). Some physiological features of asporogenous mutants of bacilli. (English translation.) Microbiology (U.S.S.R.) 29, I47-1 50.

Ionesco, H. \& CAMI, B. (1969). Utilité des marqueurs de sporulation pour établir la continuité du chromosome de Bacillus subtilis. Compte rendu hebdomadaire des séances de l'Académie des sciences 269, 975-977.

Ionesco, H., Michel, J., Cami, B. \& SchaefFer, P. (1970). Genetics of sporulation in Bacillus subtilis MARBURG. Journal of Applied Bacteriology 33, 13-24.

Karamata, D. \& Gross, J. D. (1970). Isolation and genetic analysis of temperature-sensitive mutants of B. subtilis defective in DNA synthesis. Molecular and General Genetics 108, 277-287.

Kelly, M.S. \& Pritchard, R. H. (1965). Unstable linkage between genetic markers in transformation Journal of Bacteriology 89, I314-I32I.

LACKS, S. \& HotchKISS, R. D. (I960). A study of the genetic material determining an enzyme activity in pneumococcus. Biochimica et biophysica acta 39, 508-518.

Mahler, I., Neumann, J. \& Marmur, J. (1963). Studies of genetic units controlling arginine biosynthesis in Bacillus subtilis. Biochimica et biophysica acta 72, 69-79.

Piggot, P. J. \& Mandelstam, J. (1972). Physiology and genetics of some asporogenous mutants of Bacillus subtilis. Proceedings of the International Symposium on the Genetics of Industrial Microorganisms (Prague, 1970) (in the press).

Rogolsky, M. (1969). Chromosomal regions which control sporulation in Bacillus subtilis. Canadian Journal of Microbiology 15, 787-790.

Rouyard, J. F., IonesCo, H. \& SChaffFer, P. (1967). Classification génétique de certains mutants de sporulation de Bacillus subtilis marburg. Annales de l'Institut Pasteur 113, 675-683. 
RUtBERG, B. \& HoCH J. A. (1970). Citric acid cycle: gene-enzyme relationship in Bacillus subtilis. Journal of Bacteriology 104, 826-833.

SCHAEFfer, P. \& IONESCO, H. (1960). Contribution a l'étude génétique de la sporogenèse bactérienne. Compte rendu hebdomadaire des séances de l'Académie des sciences 25I, 3125-31 27.

SpIzizen, J. (1965). Analysis of asporogenic mutants in Bacillus subtilis by genetic transformation. In Spores, vol. III, pp. I25-137. Edited by L. L. Campbell \& H. O. Halvorson. Ann Arbor, Michigan: American Society for Microbiology.

TAKAHASHI, I. (1969). Genes controlling sporulation in Bacillus subtilis. In Spores, vol. Iv, pp. IO2-I I. Edited by L. L. Campbell. Bethesda, Maryland: American Society for Microbiology. 